The Validity of Aquinas' Third Way

BY

REM B. EDWARDS

[Reprinted from The New Scholasticism, XLV, 1, Winter, 1971.] 
DISCUSSION ARTICLE III:

\section{The Validity of Aquinas' Third Way}

\section{by Rem B. Edwards}

In a recent IIind article, ${ }^{1}$ I attempted to show that the basic argument in Aquinas' "third way" was not logically fallacious, however questionable the truth of some of its premises might be. Even more recently, Thomas Mautner ${ }^{2}$ has attempted to show that I failed to demonstrate the validity of the basic pattern of reasoning which I believe to be involved in this proof. I think that he has not succeeded, though he may have shown that in producing what I believe to be a logically valid version of the cosmological argument, I was more original than I had at first thought myself to be. Since his treatment of my position is very brief, I shall quote what he has to say and then try to give an appropriate response.

(A) Suppose that we have an argument of the form $\mathrm{P}$ therefore C, and that this argument is invalid.-It could always be said that $P$, therefore $C$, is valid-although-enthymematic: the suppressed premiss being $Q$, where $Q$ entails $P \supset C$. This would be to say that there are no logical fallacies. (At worst, an argument would be enthymematic!) ${ }^{3}$

This is an interesting problem, not just for my treatment of the "third way," but for logicians and writers of introductory logic textbooks in general. Philosophers do have a problem of agreeing upon criteria to be used for " sameness of argument." We can make these criteria very strict and insist upon evaluating each argument simply on the basis of what is explicitly given, just as it is given. With such strict criteria we shall not find very many good arguments outside of the confines of textbooks on logic where we are told in advance to treat certain arguments as enthymemes and

\footnotetext{
${ }^{1}$ Rem B. Edwards, "Composition and the Cosmological Argument," Mind, LXXVII, 115-17.

'Thomas Mautner, "Aquinas's Third Way," American Philosophical Quarterly, 6, 298-304.

Ibid., 301-302.
} 
others as invalid or valid, and the suspicion of many undergraduates will be confirmed that logic is useless once we get outside the confines of the contrived exercises at the end of the chapter. Mautner seems to be opting for the Scylla of such strict criteria for "sameness of argument," fearing the Charybdis of the upposite extremehaving to regard every "invalid" argument as an enthymeme. Ha is quite correct in maintaining that with the addition of just the right premises, any invalid argument may be converted into a valid argument; so there is this danger to be dreaded as well. How shall we ever find examples of invalid arguments to give as exercisea in our logic textbooks if we go this far? However, there is also the peril of having to quit writing and talking about enthymemes altogether, and this we may also want to resist. Most professional fhilosophers do not believe that recognizing some arguments, which are otherwise invalid, as enthymemes and supplying additional premises to bolster them up commits them to the extreme view that all invalid arguments are valid enthymemes. This may be only because they do not sen the end of the road however, and Mautner may be quite correct in insisting that this is what it finally comes to. Certainly there are inescapable elements of subjectivity in ascertaining what an original arguer might have had "in the back of his mind" or that he "would have accepted if asked" or "would have accepted if he had reflected enough" or the like. My own inclination would be to apply very generous criteria for "sameness of argument." If this finally implies that all invalid arguments are enthymemes, I think that we should just have to live with it. There are methodological considerations underlying such generosity, however. Aside from wanting logic to be applicable beyond the artificial exereises given in logic textbooks, I also do not think that a philosopher can take any great pride in refuting his opponent at his weakest. But if it is possible to do him in after giving him the benefit of the doubt, then this is a significant philosophical achievement. If at its strongest a philosophical position will not bear up under examination, then we have the best of reasons for rejecting it.

(B) Correctly, Edwards draws attention to the fact that although in general arguments of the form: "all parts of $\mathrm{W}$ are $\mathrm{F}$; therefore $\mathrm{W}$ is $F$," are invalid, some arguments of this form may still be valid, not in virtue of having that form, but in virtue of some other feature. ${ }^{4}$

Ibid., 302. 
Although I agree that all arguments of the suggested form are invalid, I explicitly deny that "some arguments of this form may still be valid." If I held such a position I would be contradicting myself, and this I have not done. Arguments from part to whole may be valid by virtue of having some other form, but not by virtue of having just that form. I also do not hold that such arguments are "in general" invalid. In the somewhat technical and precise sense in which logicians use the terms "valid" and "invalid," there is no such thing as "in general" validity or invalidity. If an argument form is such that it is possible in only one instance for all its premises to be true and its conclusions false, that form is simply invalid, not just rarely valid but in general invalid.

Having admitted that all arguments of the form "all parts of $W$ are $\mathrm{F}$; therefore $\mathrm{W}$ is $\mathrm{F}$ " are invalid, I must now point out that this is not the form of the argument which I used in my re-wording of Aquinas" "third way." The form which I used was perfectly valid, having no possible substitution instances with all true premises and a false conclusion. The form which I used was: "If all parts of $\mathrm{W}$ are $\mathrm{F}$, then $\mathrm{W}$ is $\mathrm{F}$; and all parts of $\mathrm{W}$ are $\mathrm{F}$; It follows that W is F." Arguments of the form "If $p$, then $q$; and $p$; therefore q" are perfectly valid, though they may have false premises and for this reason fail to be sound. It is the latter form only which figures in my treatment of the cosmological argument. Since our concern of the moment is with the validity of the form of the argument, not with its soundness, consider once more the form of each of the following versions of the cosmological argument. These arguments have the same form as each of my examples in my earlier article.

(1) If each of the parts of nature is contingent, the whole of nature is contingent.

Each of the parts of nature is contingent.

Therefore, the whole of nature is contingent.

(2) If each of the parts of nature did not always exist, then the whole of nature did not always exist.

Each of the parts of nature did not always exist.

Therefore, the whole of nature did not always exist.

If it is too enthymematic to attribute (1) and (2) to St. Thomas himself, then let us evaluate them on their own merits. Whether 
he said it or not, we certainly have valid cosmological arguments here, even if we are unable to identify them as sound due to the presence of false or questionable premises.

But Edwards has not given any convincing reason why the Third Way should be regarded as a special case. The reason he offers is that the first premiss above (which he takes Aquinas to have tacitly assumed) is true in experience. "Experience does not show us a whole which always existed even though each of its parts did not always exist."

Certainly, experience does not show us of any whole that it always existed. Consequently, statements about such wholes cannot be empirically confirmed or disconfirmed. But surely the absence of disconfirmation cannot be taken as confirmation in a case like this! 5

We should carefully note that we are no longer debating the question of the validity of the argument-forms offered, and have turned to the question of the truth of the premises. I made no attempt to defend the second premises of my cosmological arguments in my earlier article, though I hoped to stimulate others more knowledgeable than I about such matters to debate the issue. However, I did commit myself to the claim that experience seems to confirm the truth of the first premises as I stated them. Mautner's rejoinder is that such premises are not empirical, being neither verifiable nor falsifiable. Let us now turn to such matters.

There are many Thomistic scholars who suspect that St. Thomas made a mistake in introducing the "time" argument as an integral part of his "contingency" argument, for (2) begins to look like a philosophical proof for the creation of the spatio-temporal universe ex nithilo, a proof which elsewhere he declines to give on the grounds that reason cannot disprove the Aristotelian doctrine of the aeveternity of the world (the co-existence of some ingredient or state of the world with God throughout an infinite past). That is, he usually doubted that we could establish the truth of the second premise of (2) above, though he seems to argue for its truth in the "third way" on the grounds that in an infinite amount of time, all possibilities, including the one expressed in the second premise of (2) above, would be actualized. However, he also insisted that his proof of the contingency of the world of nature as a whole is sound even if that world is in some sense everlasting. In other words, he held that both premises of argument (1) are

${ }^{5}$ Ibid. 
true and can be known to be true even if the truth of the second premise of argument (2) cannot be demonstrated by reason, and must be believed only on the basis of revelation. I am also suspicious in some ways about (2), and am inclined to regard (1) as a logically independent version of the cosmological argument the soundness of which is highly defensible.

I did say in my earlier article that I regarded "If all the parts of a whole did not always exist, then the whole itself did not always exist" as true because experience does not present us with any wholes which always existed even though each of its parts did not always exist;" that is, because experience presents us with no instances in which the antecedent of this hypothetical assertion is true and the consequent is false. In the context of the "third way," another way of saying the same thing is that "if all of the parts of nature at some time did not exist, then the whole of nature at some time did not exist." Again I would hold that we are confronted in experience with no cases in which the antecedent is true and the consequent is false. But the reason for this, as Mautner insists, may be that neither the antecedent nor the consequent is an empirical assertion, subject to confirmation or disconfirmation by experience. And there are two quite distinct charges involved here, first that the assertions are not empirical at all, and secondly that experience fails to show them to be true, that the assertions are neither verifiable or falsifiable nor verified or falsified.

Concerning the scope of the concept of the "empirical," even the experts are not inclined to agree; but I suspect that serious difficulties would ensue if one classifies as "non-empirical" any statement whose contradictory, or contrary can be confirmed or disconfirmed by experience. The time factor becomes important in a few specially interesting cases, because our "three score years and ten" will not allow us to be around long enough to confirm or disconfirm them, though it often does permit us to confirm or disconfirm their contradictories or contraries. For example, most of us would regard "some men are not mortal" as empirical despite the fact that we would have to be around forever to confirm it, and we generally regard it as false because experience seems universally to confirm its contradictory, "all men are mortal" and to disconfirm its contrary "No men are mortal."

Mautner maintains that my first premise in (2) is non-empirical, i. e., neither confirmable nor confirmed, because "experience does 
not show us of any whole that it always existed." I submit that this is not because the expression is non-empirical. This expression is equivalent in meaning to "No whole always existed," and this would be contradicted by "Some whole has always existed," which still looks non-empirical, in the same deceptive way in which "Some men are not mortal" at first may strike us as non-empirical. It has as its contrary "all wholes have always existed," which is contradicted by "Some wholes have not always existed," and this is clearly confirmable and also well confirmed in experience. There is birth and death, generation and corruption. This implies the falsity of "all wholes have always existed." The problem is, can the contrary of an obviously empirical proposition fail to be an empirical proposition? What if there is overwhelming empirical evidence for the contrary? What if every whole given to us in experience has not always existed, i.e., has come into being at some definite point in the past? This certainly seems to be the case.

Something very much like this may be the case with the antecedent of "If all the parts of nature at some time did not exist, then the whole of nature at some time did not exist." We certainly have not experienced a part of nature which at some time did not exist. This is not because the assertion is non-empirical. Rather it is because the assertion that "all the parts of nature at some time did not exist" is not only confirmable but also is so well confirmed in experience-in something like the way in which "all men are mortal" is confirmable and well confirmed in experience. True, we have not literally experienced all the parts of nature, but we have not literally experienced a!l men either. Very few universal affirmative propositions of this scope are susceptible to conclusive confirmation. All we can say is that as far as experience takes us, this seems to be the case, and we have no good reason for expecting otherwise. At least we know that experience is relevant and that all of it seems to be on one side rather than the other of this issue. To say that we have not experienced a part of nature which at some time did not exist is not to say that experience can neither confirm nor disconfirm what we say. Rather, it is to claim, correctly, that experience universally confirms the contradictory assertion that all the parts of nature at some time did not exist, to say nothing of the subalternate claim that some parts of nature at some time did not exist. Experience fails to confirm the contrary assertion that no part of nature at some time did not exist. To put the 
point another way, the claim that "some part of nature always existed" is experientially false because experience so universally confirms the contradictory claim that "No part of nature always existed," or the equivalent claim that " each part of nature did not always exist." We have experienced no part of nature which always existed precisely because every part of nature which we have experienced has not always existed but has come into being at some definite point in time.

Is St. Thomas Aquinas well knew, experience shows us that many things are subject to birth and death, generation and corruption. Horses, men, planets, solar systems-all are examples as far as we can tell. In other words, experience well confirms the proposition "Some parts of nature have not always existed." The truth of this proposition implies the falsity of the contradictory claim "All parts of nature have always existed." This universal proposition is, in turn, the contrary of "No part of nature has always existed;" and even though its truth ralue is undetermined on the basis of logic alone, it is not undetermined on the basis of experience. No experienced parts of nature have always existed, and we have experienced many, many such parts of nature. All men are mortal, and experience has again and again confirmed it. All parts of nature have come into being at some definite time in the past, and experience has again and again confirmed it-not conclusively, to be sure, for we have not experienced literally all the parts of nature any more than we have experienced all men. But it is about as well confirmed as a universal affirmative proposition of this scope ever gets. "Some men are not mortal" lacks confirmation because its contradictory is so well confirmed, though not conclusively confirmed. So it is also with "Some parts of nature have always existed."

I thus conclude that experience provides us with every good reason to believe that if each of the parts of nature did not always exist, then the whole of nature did not always exist. Granted that our experience is limited, it is nevertheless about all that we have to go on in such matters. As far as it will take us, experience does show that each of the parts of nature did not always exist, and it further shows us that if any whole is composed of parts which originated at some point in time, then the whole itself originated at some point in time. Thus we cannot find a whole which always existed, but each of whose parts did not always exist. 
Very similar considerations apply when we turn to 1 ), the contingency argument. I regard this as the strongest version of the cosmological argument, for it does not depend for its soundness upon the non-existence of nature at some point in the finite past and thus may avoid the paradox of "a time when there was no time." Experience does seem to show that if each of the parts of any whole is contingent, the whole is itself contingent. To claim at this point that nature as a whole is an exception to this would be merely to beg the question, and as far as experience takes us it does seem that each of the parts of nature is contingent. In saying that they are contingent, we mean that they are capable of nonexistence and depend upon something other than themselves for their existence. Contingent things might or might not be, and if they are at all, their being is not a self-sufficient form of being. Again, all the things given to us in experience do seem to be contingent in just this sense. "All the parts of nature are contingent," is well confirmed as far as experience will take us. Once more, we do not have much else besides experience to go on in such matters, even if conclusive confirmation is lacking. Certainly the contrary assertion that "No part of nature is contingent" is falsified, for experience confirms its contradictory "Some part of nature is contingent." Remember again our encounters with birth and death, generation and corruption. Experience fails to confirm "Some part of nature is not contingent," not because this is not an empirical proposition, but because its contradictory "All parts of nature are contingent" is so well confirmed. In the same sense, experience fails to confirm "Some men are not mortal," not because it is not an empirical proposition, but because its contradictory "All men are mortal" is so well confirmed. If experience does not acquaint us with any non-mortal humans, this is because it does acquaint us with so very many mortal humans. Similarly, if experience fails to acquaint us with some part of nature which is not contingent, it is because it does acquaint us with so very many parts of nature which are contingent. Where shall we find an exception? Furthermore, experience also shows that if any whole is composed entirely of contingent parts, then the whole itself is contingent. As far as experience will take us, we thus have every good reason to believe that if nature as a whole is composed entirely of contingent parts, it is itself contingent. In one sense, of course, we do not know that there are no necessary parts of nature, for we 
have not experienced them all. "All parts of nature are con. tingent" is not conclusively verified. Some philosophers, such as the Greek atomists, were confident that some parts of nature (the atoms) were necessary, i. e., incapable of not existing and possessing a self-sufficient form of existence. Since there is now no good reason for thinking that such claims are non-empirical, even modern day philosophers might profitably turn to the question of whether they are true. What light does the splitting of the atom shed upon such problems? I hope that someone more knowledgeable than I about such matters will take up the issue and enlighten us. Where shall we turn in the macrocosm or microcosm to find a part of nature which is not contingent? I suspect that we have not found and will not find one, and that the proposition "all of the parts of nature are contingent" is true.

As to wholes which exist permanently (relatively), experience, on the contrary, does show us that their parts need not exist permanently. Take for instance round-the-clock pop-music broadeasts. ${ }^{6}$

I must say that I fail completely to see the relevance of this final remark unless it is here being assumed that even if an argument does not commit the fallacy of composition, at least it must commit the fallacy of division. Nowhere do I even hint at the suggestion that each part of some whole must possess the properties possessed by that whole, and I certainly do not argue that each of the parts of nature must be permanent since the whole of nature is permanent.

Arguments from whole to part, commonly recognized as "division" argument, may also be treated as enthymemes however, having a perfectly valid argument form. They may be regarded as having the form "If a whole possesses a certain property, then cach of its parts possesses that property; and a whole possesses a certain property ; therefore each of it parts possesses that property." There may actually be sound arguments of this form, if some such arguments have all true premises as well as a valid form. What then would be wrong with the following argument? "If a whole concert is (relatively) permanent, then each of its parts is (relatively) permanent; and the whole concert is (relatively) permanent; therefore each of its parts is (relatively) permanent.

- Ibid. 
(We might produce an analogous argument suffering from none of the ambiguities of "is [relatively] permanent" by substituting "lasts exactly one hour" wherever this appears.) This argument is perfectly valid in form, but it obviously does not prove the truth of its conclusion. Why not? Because this valid argument has at least one false premise. Experience does show us many cases where the antecedent of the first premise is true and the consequent is false.

Since Mautner gives us no clues for distinguishing premises from conclusion in his example, perhaps he does want the argument to run the other way after all, i. e., from parts to whole, and thus be a "composition" argument. Treated as an enthymeme, this would be: "If each of the parts of a concert is impermanent (or lasts one hour), then the whole concert is impermanent (or lasts one hour); and each of the parts of a concert is impermanent (or lasts one hour); therefore the whole concert is impermanent (or lasts one hour)." Now this is again a perfectly valid argument. Its only fault is that its first premise is false, since we do find in experience that the parts of our concert last an hour each and that the whole lasts all night, or however long pop concerts usually run.

University of Tennessee, Knoxville, Tennessee. 